\title{
LA RELIGIOSIDAD DE JORGE LUIS BORGES \\ A PROPóSITO DE SWEDENBORG
}

POR

\author{
J. A. ANTON-PACHECO \\ Universidad de Sevilla
}

Muy posiblemente Jorge Luis Borges sea el autor de lengua española que más haya tratado a Swedenborg ${ }^{1}$. Este hecho es, de por sí, ya digno de considerarse. Además esta relación suscita otro tema: la conexión que pueda existir entre filosofía y literatura. En el caso concreto de Swedenborg y Borges el problema se plantea de la siguiente forma: ¿qué aporta el argentino para una mejor inteligencia del sueco? y ¿en qué medida la obra swedenborgiana ilumina la obra borgeana?

Las repetidas citas de Swedenborg en la obra de Borges no deben extrañarnos demasiado, ya que Borges es un escritor que hace uso frecuente de filósofos (Platón, Spinoza, Schopenhauer, etc.) y Swedenborg ha sido un pensador de influencia sobre todo en literatos. Sin querer hacer una nómina exhaustiva de todas las referencias borgeanas al Profeta del Norte, vamos a exponer las más importantes y claras, ya que éstas nos dirán lo que a Borges le interesa de Swedenborg y tal vez también lo que el argentino pueda añadir al conocimiento del teólogo sueco.

Existen dos textos en los que Borges ensaya una especie de síntesis doctrinal swedenborgiana: uno de ellos es un prólogo a una edición en lengua inglesa de Swedenborg'; ; el otro (prácticamente igual al anterior, sólo que algo abreviado) es el texto de una conferencia pronunciada en la universidad de Belgrano en 1978 y recogida en el volumen Borges Oral ${ }^{3}$. Estos sumarios resúmenes, a pesar de algunas inevitables imprecisiones debido a su cortedad, están bien confeccionados y nos dan, además, idea cabal de lo que más le pudiera interesar a Borges de Swedenborg: ante todo la lucidez del visionario sueco (contra todos los tópicos al respecto) y el rechazo de toda atribución de locura a éste. Esta comprobación de la lucidez swedenborgiana por parte de Borges

\footnotetext{
${ }^{1}$ Cf. nuestros "Swedenborg y Unamuno", Pensamiento 169,1987, 42-57, y "Presencia de Swedenborg en Eugenio D'Ors", Heterodoxia 1 . 1988, 7-9.

${ }^{2}$ Prólogos, Buenos Aires: Torres Agüero editor, 1975, 153-62. El prólogo en cuestión es a la obra Mystical Works.

${ }^{3}$ Borges orah Barcelona: Ed. Bruguera, 1980, 49-67.
} 
significa, en primer lugar, la antesala necesaria para cualquier tránsito hacia Swedenborg (sólo porque éste tiene algo que decir es posible una subsecuente indagación); y en segundo lugar, la necesidad de una determinada interpretación de los escritos de Swedenborg, esto es, que no es posible una correcta comprensión del teólogo escandinavo sin una hermenéutica ad hoc. Después de esto, existen varias notas interesantes que Borges ha sabido detectar en el sabio nórdico, como la mención del carácter formal, concreto, individual, de los mundos suprasensibles; pero sobre todo nos interesa lo que afecta a lo que pudiéramos llamar la religiosidad de Borges: "Según Swedenborg, el Infierno y el Cielo están en el hombre, que asimismo incluye planetas, montañas, mares, continentes, minerales, árboles, hierbas, flores, abrojos, animales, reptiles, pájaros, peces, herramientas, ciudades y edificios"4. Aquí puede estar la llave de la atracción de Borges por Swedenborg: se trataría en definitiva de la interiorización de ámbitos y categorías normalmente proyectados ad extra. La obra (y la religiosidad) de Swedenborg sería entonces un proceso por el que el alma vive en su interior lo que otros colocan fuera. Todos esos "planetas ... etc.", son ahora los movimientos, los flujos, las transformaciones y explanaciones de la conciencia. Es en el alma donde residen todos aquellos, pues son sucesos del alma, es decir, lo que vive el alma. En el impresionante soneto que Borges dedica a Swedenborg se recoge la misma idea:

Sabía que la Gloria y el Averno en tu alma están y sus mitologías ${ }^{5}$

Así, pues, lo que Borges ha intuido en la obra swedenborgiana es lo que Henry Corbin ha desarrollado in extenso: una fenomenología de la conciencia visionaria, donde los viajes, las epopeyas y los mundos descritos con pintoresco color son metáforas e imágenes de las realidades del espíritu ${ }^{6}$. La lectura que Borges hace de Swedenborg es, en cierta medida, comparable a la hecha por Strindberg, pues también para éste el cielo y el infierno swedenborgianos son interiorizaciones de la conciencia que vive el cielo o el infierno ${ }^{7}$. Es decir, cada

${ }^{4}$ Prólogo, 161.

${ }^{5}$ Obra poética, Madrid: Alianza Editorial, 1972, p. 222.

${ }^{6}$ No hay obra de Henry Corbin donde no se trate la figura de Swedenborg. Pero su trabajo clásico sobre el pensador nórdico es "Herméneutique spirituelle comparée (I Swedenborg. II Gnose Ismaélienne)", Eranos-Jahrbuch XXXIII 1964 71-76.

7 "La lectura de Swedenborg ocupa toda mi jornada; y me aplasta el realismo de sus descripciones. Todo se encuentra en ellas, todas mis observaciones, mis sensaciones, mis ideas, de tal modo que sus visiones me parecen vividas, como auténticos documentos humanos. No es preciso creer ciegamente; basta con leer y comparar con las propias experiencias vividas", Inferno, p. 185. Traducción de José Rodríguez, Barcelona: Ed. Fontamara, 1981. En Strindberg el paralelismo entre la interiorización swedenborgiana y la suya propia es más existencial. Para Strindberg el infierno descrito por Swedenborg fue vivido por su particular descensus ad inferos. 
uno es su cielo o su infierno. Cielo e infierno son así representaciones de experiencias interiores, de la misma manera que las moradas de Santa Teresa o los castillos de Sohravardi representan procesos y eventos de la interioridad y sus estados. Otra referencia a Swedenborg insiste sobre este interés del escritor hispano en lo que podríamos llamar religiosidad interior o interiorización de imágenes y figuras religiosas: “Para Swedenborg, como para Boehme, el cielo y el infierno son estados que con libertad busca el hombre, no es un establecimiento penal y un establecimiento piadoso" ${ }^{\text {. Posiblemente las }}$ consecuencias que Borges pudo sacar de esta interpretación de Swedenborg fueran de índole tanto estética como filosófica o espiritual. Estética, por las posibilidades latentes que supone el aserto de la preeminencia de la interioridad; filosófica o espiritual, por el modo especial de religiosidad que implica la vivencia interior. Tal vez sea excesivo incluir a Borges dentro de lo que llamaríamos la espiritualidad swedenborgiana, pero es indiscutible que Borges sentia por Swedenborg una atracción algo más que culturalista ${ }^{9}$. Borges ha intuido que lo que Swedenborg nos dice; hace referencia, antes que nada, a realidades del alma. Según esto, el Buda del Norte vendría a proponer una religiosidad interiorizada, espiritualizada; en cierto modo una religiosidad desmitologizada, en la que las imágenes y representaciones se resuelven en experiencias del alma. Este aspecto desmitologizante de la hermenéutica swedenborgiana, en el fondo propio de toda exégesis alegórica, ha sido bien percibido por Borges, quien ha entrevisto la idea fundamental que subyace el pensamiento del visionario escandinavo. Así, pues, si para Unamuno Swedenborg sería como un precursor de la filosofía de la existencia; si para D'Ors un teórico de la angelología, Borges resaltaría a aquél como un pensador de la interioridad de la conciencia. Indudablemente, las consecuencias filosóficas y teológicas de toda esa concepción swedenborgiana tienen enormes posibilidades de desarrollo. Pero ya hemos dicho que Borges se queda en la intuición de esas ideas, y por otrolado, hay que pensar que no es él un swedenborgiano en estricto sentido, ni filósofo, ni teólogo, y que por lo tanto tampoco tenemos que esperar de él una exposición completa y detallada de las teorías del sueco. Pero el interés que suscita Swedenborg en Borges es manifiesto. Lo prueban las seis inclusiones de textos swedenborgianos (más que ningún otro autor) en "El libro del cielo y del infierno ${ }^{m 0}$, más otro texto de Heine que supone una interesante reflexión sobre Swedenborg, también dentro de la línea que ve en el profeta del

\footnotetext{
${ }^{8}$ Otras inquisiciones, p. 137. Buenos Aires, Emecé Editores, 1966.

${ }^{9}$ Para Oswaldo Romero es indiscutible la influencia de Swedenborg sobre la religiosidad o espiritualidad borgeana, como lo expone en "Dios en la obra de J. L. Borges: su Teologia y su Teodicea", Revista Iberoamericana, 100-1 (1977). Se trata de un número monográfico dedicado a Borges.

${ }^{10}$ Libro del cielo y del infierno (en colaboración con Bioy Casares), Barcelona: EDHASA, 1971, p.40, 43, 61, 62, 155, 174. En lo que respecta a Heine, p. 187.
} 
Norte a un pensador en el que prima antes que nada la individualidad concreta, la interioridad de la conciencia, el impulso hacia la forma. Asimismo, en "Cuentos breves y extraordinarios" ${ }^{\prime 11}$ nos encontramos con otra referencia a un texto de Swedenborg. Por último, en "Otro poema de los dones" encontramos como un reconocimiento general de su figura:

Por Swedenborg, que conversaba con los angeles en las calles de Londres ${ }^{12}$

En resumidas cuentas, creemos que Swedenborg inspira a Borges una determinada manera de experimentar la religiosidad. Dejamos esta palabra en toda su ambivalencia, porque no está muy claro que el escritor argentino se afirmara en una religión positiva. Pero sí parece evidente que participaba de sentimientos y vivencias de auténtica religiosidad. $Y$ en estos sentimientos y vivencias el papel de Swedenborg es sobresaliente: proceso de interiorización, exégesis desmitologizadora, espiritualización de categorías formuladas en proyección ab extra, vida religiosa en cuanto que espontaneidad de la conciencia ... en todas estas expresiones de la actividad del alma late la huella swedenborgiana. Pero si la influencia de una cierta espiritualidad en Borges es importante, no lo es menos el hecho de que éste haya sabido interpretar y extraer tan inteligentes notas de un autor que, como Swedenborg, no ha gozado a menudo de lecturas tan lúcidas. Por eso importa aquí no sólo lo que haya podido suponer la obra de Swedenborg en Borges, sino también lo que éste ha podido aportar de iluminación para una mejor comprensión del sabio sueco. Y por tanto, si la presencia swedenborgiana nos puede hacer conocer mejor no sólo la literatura sino también la más íntima religiosidad de Borges, ciertamente las intuiciones de éste nos permiten aportar datos a la hora de abordar la interpretación de un autor siempre tan presto a equívocos como es Swedenborg.

No hemos apreciado en los libros de Borges ninguna otra alusión de importancia a Swedenborg. O acaso sí, indirectamente, de forma no explícita. Hablamos de un hermoso poema de indudables resonancias swedenborgianas, pues lleva el significativo título de "El Angel" y acaba diciendo:

Señor, que al cabo de mis días en la Tierra yo no deshonre al Angei ${ }^{13}$

\footnotetext{
${ }^{11}$ Cuentos breves y Extraordinarios (en colaboración con Bioy Casares), Buenos Aires: Rueda, 1967, p. 87.

${ }^{12}$ Obra poética, p. 255 . Dado que se trata de un poema de acción de gracias al "divino laberinto de los efectos y las causas", podemos colegir la importancia que adquirió Swedenborg para Borges.

${ }^{13}$ La cifra, p.67, Madrid: Alianza Editorial, 1982. ¿Pudiera existir aquí alguna conexión con Eugenio D'Ors? Léase al respecto el librito de éste Oraciones para el creyente en los ángeles, Valladolid: Miñón, 1981.
} 


\section{ADDENDA}

Existe en la literatura de Borges una referencia que, sin extremar deducciones, bien pudiera suponer un cipo a la hora de establecer la filiación espiritual borgeana. Esa señal o síntoma es Gustav Theodor Fechner. Volvemos a repetir que no es nuestra intención sacar consecuencias de lo nebuloso, sino sólo apuntar a posibles indicadores de una actitud. Y en este sentido citamos a Fechner; y más en concreto, Libro del Cielo y del Infierno, p. 142 (se trata del texto de Fechner "Extensiones", extraído de su peculiar Zend-Avesta). "Extensiones", el texto elencado por Borges y Bioy, entra de lleno a nuestrojuicio en esa tendencia propia de una religiosidad interiorista para la que teologúmenos y mitologuemas se resuelven en movimientos y estados del alma, religiosidad que en Borges conecta con motivos swedenborgianos. El citado párrafo de Fechner es exponente de lo que, siguiendo la terminología utilizada más arriba, pudiera denominarse filiación espiritual swedenborgiana. Pero resulta además que Fechner se nos presenta como tertium comparationis en otro autor también ya citado y para quien asimismo, Swedenborg ocupó un papel importante: Henry Corbin. En efecto, en el libro de Corbin Corps spirituel et Terre céleste es citado largamente Fechner en relación con un tema tan típicamente swedenborgiano como es el del ángel. Un sistema de referencias cruzadas nos insertaría en una misma secuencia a Borges con Corbin, a Swedenborg con Fechner, y a todas las posibles combinaciones entre estos autores.

Así, pues, a la hora de dilucidar la religiosidad borgeana, la intercesión de Fechner con Borges revela una característica más de esa espiritualidad e incide especialmente en ella: la vida de la conciencia y su explanación. 
